\title{
AVALIAÇÃO DA CONDUTIVIDADE HIDRÁULICA E A SUA RELAÇÃO COM \\ ESCOAMENTO SUPERFICIAL EM ÁREAS DE COLINAS SITUADAS NA BACIA HIDROGRÁFICA DO RIO SÃO JOÃO, RJ
}

\section{Evaluation of hydraulic conductivity and its relationshio with runoff in hills areas located in São João Riverwatershed, RJ}

\author{
Neiva Barbalho Morais \\ Mestre pela Universidade Federal Fluminense \\ Especialização em Geologia do Quaternário pela Universidade Federal Fluminense \\ barbalhomorais@yahoo.com.br \\ Raul Sanchez Vicens \\ Professor adjunto do Departamento de Geografia da Universidade Federal Fluminense \\ Doutorado em Geografia pela Universidade Federal Fluminense \\ rcuba@vm.uff.br \\ Ana Valéria Freire Allemão Bertolino \\ Professor adjunto da Universidade do Estado do Rio de Janeiro Procientista UERJ \\ Doutorado em Geografia pela Universidade Federal Fluminense \\ anaval@uerj.br
}

Artigo recebido em 14/03/2013 e aceito para publicação em 21/04/2013

DOI: 10.12957/tamoios.2013.5230

RESUMO O processo hidroerosivo é um fenômeno natural que vem sendo intensificado por atividades humanas, podendo resultar em degradação do solo e dos corpos hídricos. Por isso, este estudo visa mensurar as perdas de água e solo em duas parcelas de erosão, do tipo Wischmeier, em encostas cobertas por pastagem na Bacia hidrográfica do Rio São João. Além disso, realizaram-se ensaios de condutividade hidráulica saturada com Permeâmetro de Guelph. O monitoramento realizou-se no período hidrológico de outubro de 2009 a março de 2010. Durante o período estudado, as maiores perdas de água e solo atribuem-se à parcela $\mathrm{A}$, que apresenta menos sinais de degradação, resultados estes que corroboraram com os encontrados na condutividade hidráulica. Parte do resultado encontrado pode ser explicado pelo micro-terraceamento, derivado do pisoteio do gado, encontrado na parcela $\mathrm{B}$, que pode estar resultando no estocamento das águas pluviais em superfície, reduzindo as taxas de escoamento destas.

Palavras-chaves: escoamento superficial; parcelas de erosão e condutividade hidráulica.

ABSTRACT The hidroerosive process is a natural phenomenon that has been intensified by human activities, which may result in soil degradation and water bodies. So, this study aims to measure water loss and soil erosion in two erosive plots, from Wischmeier type, on slopes covered by pasture in the Baciahidrográfica do Rio São João. Moreover, trials were carried out with saturated hydraulic conductivity using Guelph permeameter. The monitoring was held on hydrological period from October 2009 to March 2010. During that period, the greatest loss of water and soil came from plot A, which shows fewer signs of degradation; these results corroborate those found in hydraulic conductivity. Part of the results found could be explained by micro-terraces, derived from the cattle trampling found in plot B which may be resulting in storage of rainwater on the surface, reducing its runoff.

Key words: runoff; erosive plot; hydraulic conductivity. 


\section{INTRODUÇÃO}

A erosão do solo depende da resistência que este oferece à dispersão e à movimentação das partículas presentes nele. Se o solo é protegido por uma densa cobertura vegetal, de uma forma geral, a erosão só ocorrerá sob pluviosidade e escoamento excessivo. Se o solo não está protegido, geralmente ocorre erosão para os menores escoamentos. Vários fatores influenciam na erosão laminar do solo, como a pluviosidade (Assouline e Ben-Hur, 2006, Pruski, 2008, Zachar, 1982, entre outros), a topografia (Campos et al. 2008, Schumacher et al, 1999, Kirkbyet al., 1996, etc), a vegetação (Greenway, 1987; Le Bissonnais, 2005, etc) e as características físicas do solo (Bertoni e Lombardi Neto, 1999, Tindallet. al., 1999, entre outros). A avaliação da erosão hídrica como parte de diagnósticos ambientaisé extremamente importante, uma vez que o uso inadequado do solo pode acelerar os processos de erosão e deposição que ocorrem naturalmente, levando a alterações relacionadas à conservação do solo, produção e qualidade da água e a mudanças ambientais em determinados locais de uma bacia hidrográfica (Blanco,2009).

Dentre as propriedades físicas do solo, sua permeabilidade eresistência à erosão são as mais importantes. A sua permeabilidade determina a quantidade do fluxo superficial, enquanto a resistência à erosão determina a proporção de partículas transportadas, o que pode ser determinado pela textura do solo (Zazhar, 1982).

As propriedades físicas do solo são facilmente alteradas pelos sistemas de preparo e utilização. Por isso, principalmente em regiões tropicais úmidas, são buscadas técnicas que propiciem mínimas perturbações nas propriedades físicas e a manutenção de resíduos na superfície. Assim, o controle da erosão é fundamental para reduzir o processo de degradação do solo e do meio ambiente (Lal, 2000; Tormenaet al., 2002).

Dentre as formas de utilização do solo, influenciadoras das propriedades físicas, o manejo de animais com diferentes lotações em pastagens naturais pode resultar no aumento da sua suscetibilidade à erosão hídrica (Bertolet al., 1998).

O presente estudo desenvolveu-se em colinas dissecadas situadas na Bacia do Rio São João, que é responsável pelo abastecimento da represa de Jurtunaíba e esta, pela Região dos Lagos, e poderá vir a abastecer as atividades industriais do Complexo Petroquímico do Estado Rio de Janeiro. Com isto, surge a necessidade de avaliar a produção de sedimentos. Os processos erosivos em áreas de encostas são um dos responsáveis pelo fornecimento de sedimento para os canais fluviais; portanto, o entendimento desse processo é essencial para propor qualquer medida mitigadora.

Segundo o Comitê de Bacias Lagos São João, atualmente, em diversas partes do curso do Rio São João, foram identificadas sinais de degradação ambiental, bem como as altas taxas de sedimentos em suspensão, fator que poderá contribuir com a redução da qualidade das águas, além de encostas degradadas associadas às práticas agropecuárias desenvolvidas na região (Bidegainet al, 2005).

Em virtude disso, este trabalho tem como objetivo mensurar as perdas de água e solo por meio de estação experimental (Figura 1), composta de duas parcelas de erosão e pluviômetros manuais, em encostas de colinas cobertas por pastagens, localizadas na Bacia Hidrográfica do alto curso do Rio São João, no Estado do Rio de Janeiro. 


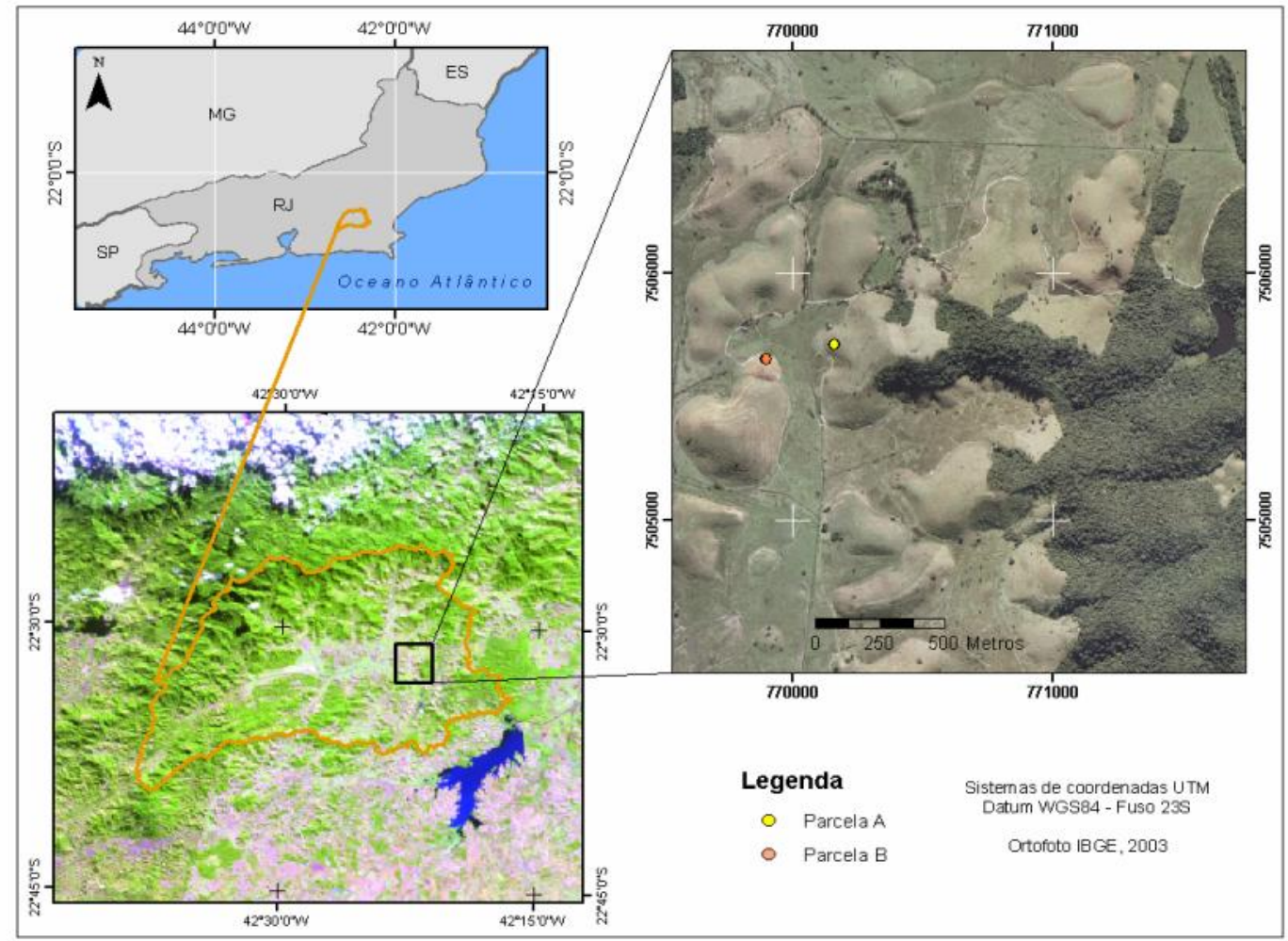

Figura 1: Localização das parcelas de erosão.

\section{MATERIAIS E MÉTODOS}

Foram escolhidas áreas de pastagens em dois estágios de degradação ambiental. Como critério de degradação, adotou-se a relação vegetação - solo exposto. Portanto, as investigações ocorreram em uma área experimental totalmente recoberta por vegetação do tipo gramínea (parcela A) e em outra com alta porcentagem de solo exposto (parcela B). A escolha de áreas com grau de degradação diferenciado visou contemplar a variância inerente às características de degradação das encostas situadas na região estudada.

Para a mensuração das perdas de água e solo, instalaram-se duas parcelas do tipo Wischmeier(Meyer e Wischmeier, 1969), (Figura 2) nas encostas cobertas por pastagem no sentido do declive, delimitadas por chapas galvanizadas, com dimensão de 22 x 4m, totalizando $88 \mathrm{~m}^{2}$. O estudo realizou-se no período de outubro de 2009 a março de 2010.

$\mathrm{Na}$ extremidade inferior das parcelas conectou-se um tanque de sedimentação (10001). O material retido no tanque é homogeneizado e retirado uma amostra de 11 ou na quantidade de escoamento proporcionada quando inferior a 11, a fim de caracterizar quantitativamente e qualitativamente o material carreado. A coleta dos sedimentos ocorre em um intervalo de 24 horas, na ocorrência de eventos pluviométricos.

As parcelas estão situadas na porção baixa da encosta, com as seguintes características:

Parcela A - declividade de 16 graus. A encosta possui $137 \mathrm{~m}$ e o topo da parcela localiza-se na cota de $47 \mathrm{~m}$ (Figura 2).

Parcela B - declividade de 27 graus. A encosta possui $44 \mathrm{~m}$ e o topo da parcela localiza-se na cota de 32 m (Figura 3). 


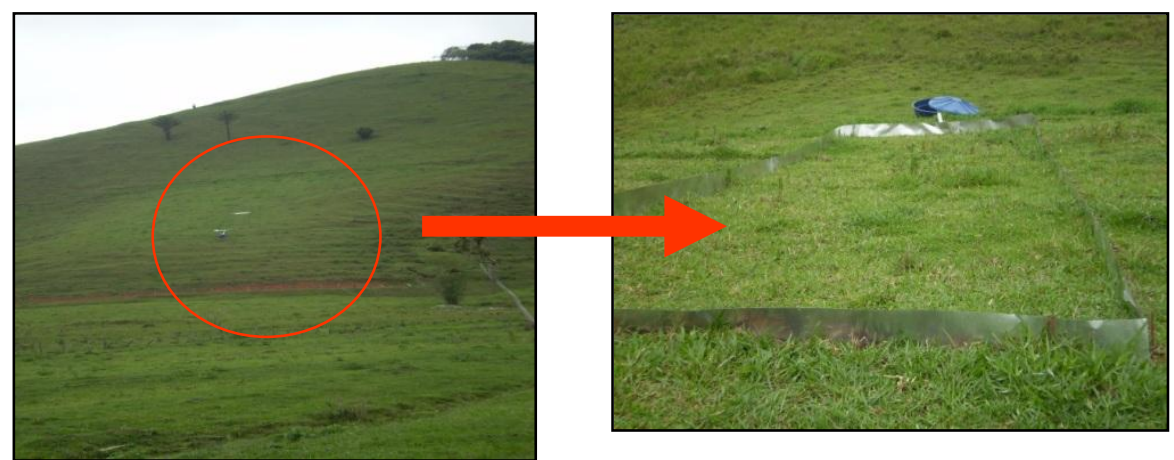

Figura 2: Detalhe da Parcela A recoberta por pastagem, situada na porção baixa da encosta.

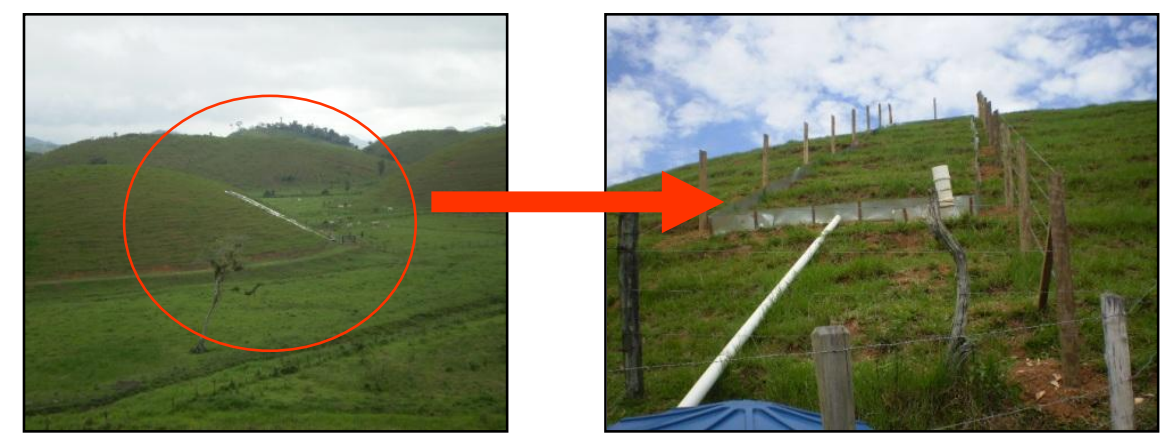

Figura 3: Detalhe da parcela B com micro-terraceamentos, situada na porção baixa da encosta.

Como unidade de referência para os ensaios das propriedades hidráulicas do solo, delimitou-se uma área experimental, na porção baixa da encosta,sob domínio de Floresta (Figura 4).

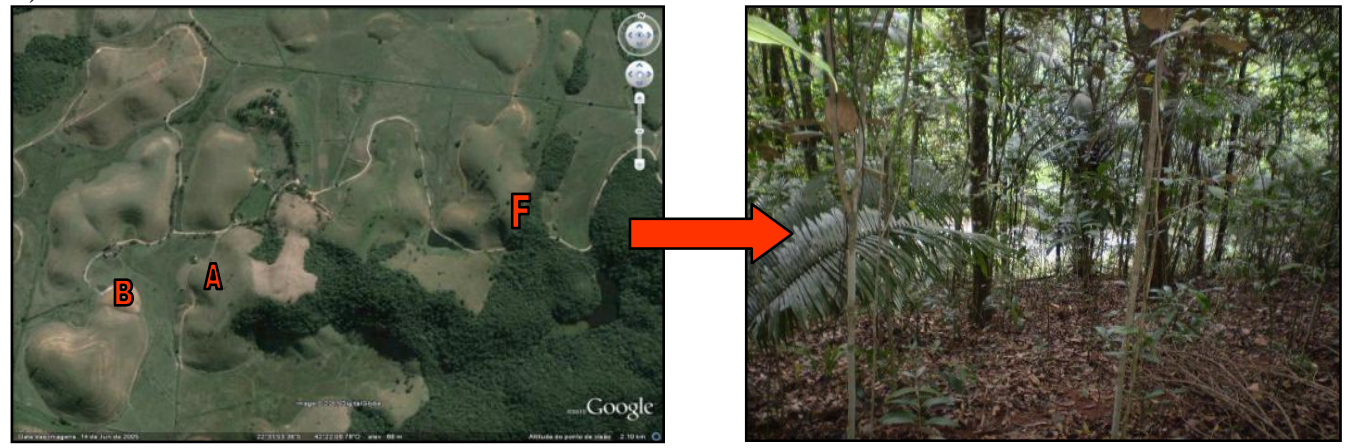

Figura 4: Localização do sítio experimental de Floresta.

As áreas de pastagens são recobertas por capim quicuia (Brachiariahumidicola), uma das forrageiras tropicais, adaptada a regiões de solos alagados ou mal drenados. Trata-se de uma gramínea perene, procedente do continente africano, a qual ocorre em áreas relativamente úmidas. Vegeta bem em regiões de solos fracos e de elevada acidez, propagando-se facilmente por sementes e mudas (Dias-Filho, 2006).

Em relação à classificação textural do solo nas áreas experimentais, segundo Morais (2001), na parcela A, nas profundidades de $0-5 \mathrm{~cm}$, a classificação textural é franco argiloarenosa. No entanto, nas demais profundidades desta parcela a classificação encontrada foi argilo-arenosa. Para a parcela B, a classificação textural em todas as profundidades foi argilosa. Na unidade da Floresta as profundidades superficiais, de 0-5 e de 5-10 cm, apresentaram textura franco-arenosa. Nas profundidades de 10-20, 20-40 e de 40-60 cm a classificação observada é franco argilo-arenosa. 
Para a estimativa da condutividade hidráulica saturada (Ksat), foi utilizado o Permeâmetro de Guelph. A fim de obter uma boa caracterização espacial da Ksat, e assim avaliar a sua relação com as perdas de água e solo, os ensaios nas parcelas foram realizados em diferentes pontos topográficos e profundidades.

A condutividade hidráulica saturada permite avaliar a capacidade que o solo possui em permitir a percolação de um fluído entre os seus espaços vazios. A baixa permeabilidade do solo está diretamente relacionada à sua compactação e resistência à infiltração, fator este que influencia na geração de runoff e na erosão dos solos.

As mensurações ocorreram nas profundidades de 15, 25 e $45 \mathrm{~cm}$, em ambas as parcelas, em seus setores alto e intermediário, utilizando-se as cargas de 5 e $10 \mathrm{~cm}$ de coluna d'água. $\mathrm{Na}$ Floresta foi delimitada uma região com a mesma área das parcelas, $88 \mathrm{~m}^{2}$. Os experimentos foram feitos nas mesmas profundidades e nos mesmos setores topográficos.

Durante o ensaio, na verdade, não se consegue obter a saturação total, e sim uma saturação de campo, pois no campo não é possível expulsar completamente o ar dos vazios. Isto não chega a ser uma desvantagem, visto que a saturação total é muito difícil de ser atingida em uma situação real. Logo, a condutividade obtida será a condutividade hidráulica da saturação de campo (Kfs - hydraulicconductivityatfieldsaturation). O Permeâmetro de Guelph é projetado para medir a condutividade entre $10^{-2}$ e $10^{-6} \mathrm{~cm} / \mathrm{s}$. Abaixo ou acima destas ordens de grandeza, as medições apresentam erros ou não se consegue realizar o ensaio(Vieira, 2001).

Para o cálculo da condutividade hidráulica do solo saturado pelo método do permeâmetro de Guelph (PG), utiliza-se a Equação 1:

$$
K s=(0,0041) \times(S) \times\left(R_{2}\right)-(0,0054) \times(S) \times\left(R_{1}\right)
$$

em que:

$\mathrm{S}$ = área da seção transversal do reservatório, em $\mathrm{cm}^{2}\left(=10^{-4} \mathrm{~m}^{2}\right)$;

$\mathrm{R}_{1}$ e $\mathrm{R}_{2}=$ taxas de equilíbrio dinâmico da queda de água no reservatório, em $\mathrm{cm} \mathrm{s-}^{1}$;

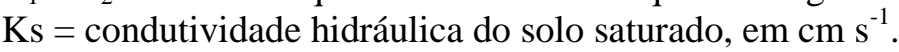

\section{RESULTADOS E DISCUSSÃO}

O ensaio da condutividade hidráulica (Ksat) foi realizado nas partes altas e médias das unidades experimentais, assim como em diferentes profundidades (15, $25 \mathrm{e} 45 \mathrm{~cm})$. No entanto, os resultados encontrados, apesar das variações em números absolutos e na ordem das potências, não mostraram diferença estatística entre as posições topográficas para o nível de probabilidade $95 \%$, com $\mathrm{T}_{\mathrm{TAB}}$ de 0,05 para o $\mathrm{T}_{\mathrm{CALC}}$ de 1,19217. Os resultados do Ksat nas partes alta e média das parcelas só apresentam diferenças significativas com $\alpha=0,5$. Portanto, os dados dos ensaios do Ksat serão discutidos a partir das médias por profundidade e por posição topográfica obtidas entre os resultados da parte alta e média da encosta.

Observando a Tabela 1 dos valores de Ksat encontrados nas unidades experimentais, estes, no geral, variaram de $5,11 \times 10^{-5}$ a $1,28 \times 10^{-3} \mathrm{~cm} / \mathrm{s}$. No sistema de Floresta, os valores médios de condutividade hidráulica nas três profundidades ficaram entre $10^{-3}$ e $10^{-4} \mathrm{~cm} / \mathrm{s}$, enquanto em ambas parcelas os valores ficaram entre a ordem de $10^{-3} \mathrm{e} 10^{-5}$. Segundo a classificação de Klute e Dirsken (1986), as condutividades hidráulicas foram baixas $\left(10^{-3} \mathrm{~cm} / \mathrm{sa}\right.$ $10^{-5} \mathrm{~cm} / \mathrm{s}$ ), tais resultados eram esperados para materiais argilo-arenosos.

Nas parcelas, os valores do Ksat sofreram um decréscimo em profundidade na ordem de dez vezes em relação à profundidade anterior, indicando, assim, uma diminuição da permeabilidade do solo. Esta redução nos valores de Ksatpodem ser associados tanto à atividade intensa da pecuária quanto à redução natural da permeabilidade em profundidade.

Na unidade da Floresta, embora tenha se obtido uma baixa permeabilidade, as variações ficaram entre $10^{-3}$ e $10^{-4} \mathrm{Ksat}$, em todas as profundidades. Vale destacar que quando são comparados os resultados de Ksat dos $25 \mathrm{~cm}$ com os de $45 \mathrm{~cm}$ de profundidade, observa-se um aumento em profundidade do Ksat na ordem de dez vezes, ou seja, uma melhora na infiltração. Esse resultado pode ser atribuído à atividade das raízes, que em áreas de Floresta tendem a ser profundas. 
Tabela 1.Valores médios da Condutividade Hidráulica saturada $(\mathrm{cm} / \mathrm{s})$ nas parcelas A, B e na unidade da Floresta.

\begin{tabular}{llll}
\hline & Parcela A & Parcela B & Floresta \\
\hline Prof. & Ksat $(\mathrm{cm} / \mathrm{s})$ & Ksat $(\mathrm{cm} / \mathrm{s})$ & Ksat $(\mathrm{cm} / \mathrm{s})$ \\
15 & $1,28 \mathrm{E}-03$ & $5,20 \mathrm{E}-03$ & $4,56 \mathrm{E}-03$ \\
25 & $5,55 \mathrm{E}-04$ & $1,51 \mathrm{E}-04$ & $5,53 \mathrm{E}-04$ \\
45 & $5,11 \mathrm{E}-05$ & $3,28 \mathrm{E}-05$ & $8,55 \mathrm{E}-03$ \\
\hline
\end{tabular}

Resultados semelhantes foram encontrados por Miguel et. al. (2009), que avaliou o efeito da intensidade de pisoteio do gado na variabilidade espacial da infiltração de água em um Argissolo Vermelho Amarelo, e observou redução gradativa da infiltração a cada passagem do gado avaliada, o que indica a ocorrência de compactação do solo em razão do pisoteio do gado. A maior redução na taxa de infiltração de água foi observada a $0,10 \mathrm{~m}$ de profundidade.

O mesmo refere-se ao estudo de Oliveira et. al. (2007), que constatou uma variação no comportamento da condutividade hidráulica em função da profundidade, em um Latossolosob coberturas de mata nativa, cultura de soja e pastagem, nas profundidades de 0,5, 1,0 e 1,5 metros. Em todas as profundidades o uso de pastagem alcançou os menores valores de condutividade hidráulica.

Visando analisar as diferenças de permeabilidade, tanto em profundidade quanto entre parcelas, foi realizada uma análise de variância bi-direcional. Os valores de F calculado são apresentados (Tabela 2). Tanto para a análise por parcelas (A, B e Floresta) quanto por profundidades $(15,25 \mathrm{e} 45 \mathrm{~cm}$ ), os graus de liberdade por tratamentos foram os mesmos (GLIB $=2$ ). $O$ grau de liberdade do resíduo (erro) foi de $G L I B=13$, logo o $F$ crítico para $\alpha=0,05$ foi de 3,81, em ambos os casos. Como os F calculados superam o F crítico, é possível concluir que há diferenças significativas na permeabilidade, tanto entre as parcelas quanto entre as profundidades.

Tabela 2: Valores de $F_{\text {calculado }}$ para análise da variação dos valores de Ksat entre as áreas experimentais e por profundidade (análise de variância Bi-direcional) $\left(F_{\text {tabelado }}=3,81\right)$.

\begin{tabular}{lll}
\hline & PA X PB X FLOR & Profundidades \\
\hline Guelph & 6,724452797 & 7,874830588 \\
\hline
\end{tabular}

Em uma avaliação detalhada dos valores absolutos do Ksat nos $15 \mathrm{~cm}$ de profundidade, a parcela B alcançou Ksat cerca de quatro vezes maior que a parcela A. Tais resultados podem ter sido influenciados pelas propriedades do solo de macroporosidade e microporosidade do solo nos $5 \mathrm{~cm}$ de profundidade, conforme comprova Morais (2011), vide Figuras 5 e 6. Com base nisso, é possível inferir que as alterações nas propriedades físicas interferem diretamente na Condutividade hidráulica saturada do solo.

Parcela A

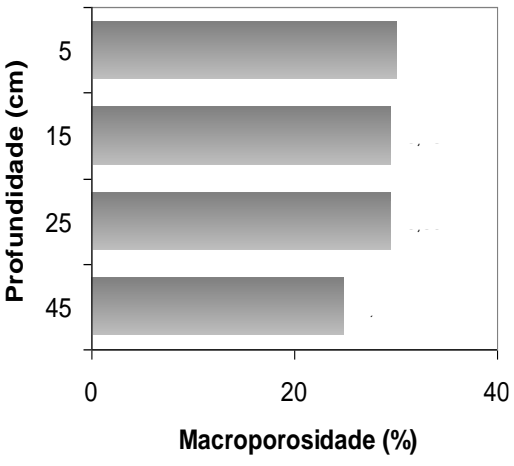

Parcela B

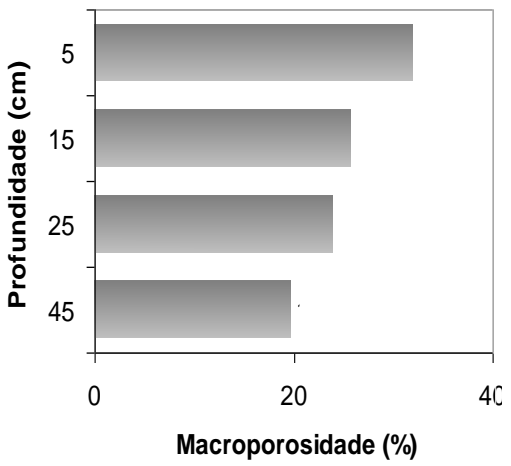

Floresta

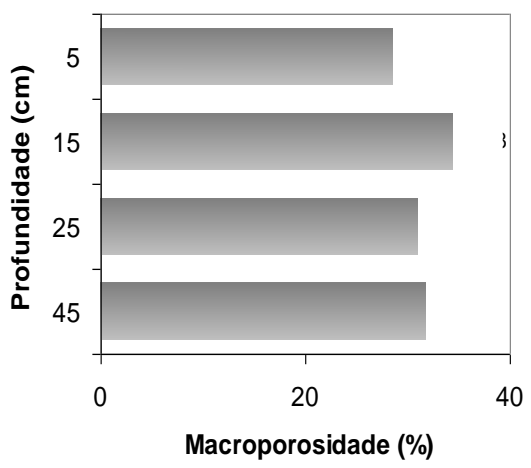

Figura 5: Teores da Macroporosidade por profundidade nas parcelas A, B e Floresta.Fonte: Morais (2011). 

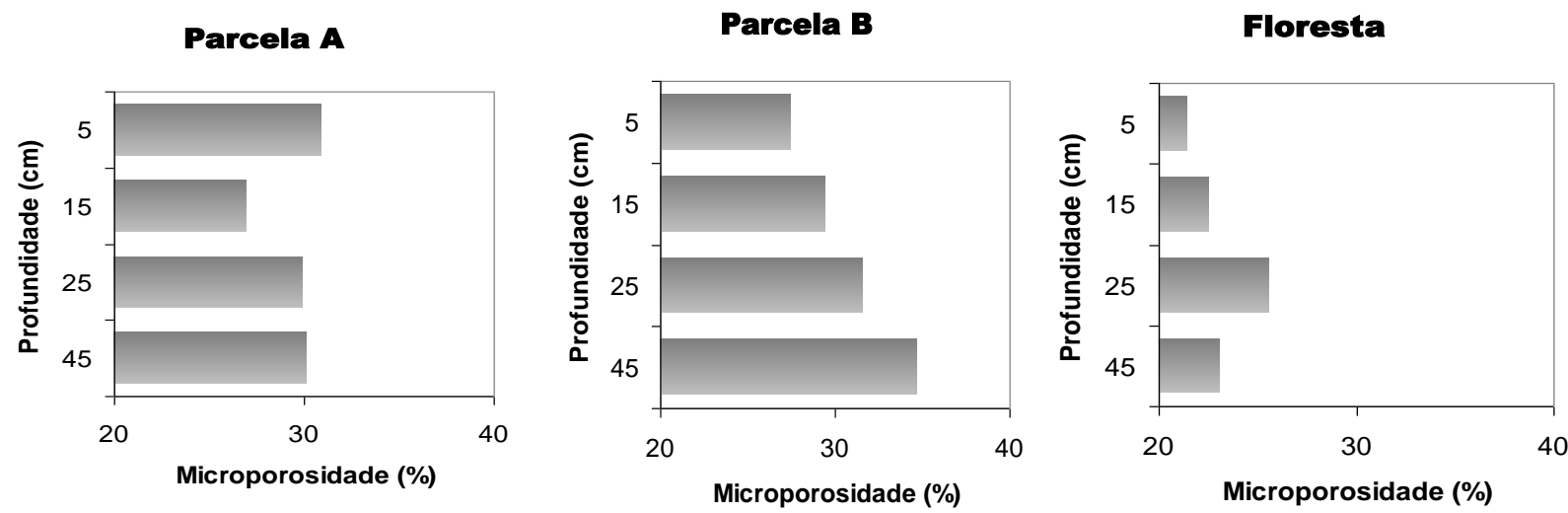

Figura 6: Teores da Microporosidade por profundidade nas parcelas A, B e Floresta. Fonte: Morais, 2011.

Nos $25 \mathrm{~cm}$ do perfil do solo, o Ksat da parcela A e da Floresta obtiveram valores similares, cerca de 3 vezes maior que a parcela B. Os teores de macroporosidade dessas unidades experimentais são similares, o que pode ter condicionado os valores do Ksat. O menor valor absoluto adquirido pela parcela $\mathrm{B}$ pode ser explicado pelas variáveis de porosidade, uma vez que nessa altura do solo, a parcela B, em comparação com as outras áreas, obteve as maiores e as menores proporções de macroporos. Salienta-se que este resultado também pode ser atribuído à classificação textural da parcela $\mathrm{B}$, que é argilosa.

A condutividade hidráulica pode variar de acordo com a tipologia dos materiais, isto é, se o material for mais arenoso há uma tendência da condutividade hidráulica ser maior. Por outro lado, se nos depararmos com um material mais argiloso, a permeabilidade será menor.

$\mathrm{Na}$ profundidade de $45 \mathrm{~cm}$ da unidade experimental Floresta, o valor de Ksat aumentou, enquanto as duas parcelas tiveram uma diminuição na ordem de dez vezes, quando comparadas com o Ksat registrado na profundidade de $25 \mathrm{~cm}$. Concordando com o comportamento da macroporosidade, no qual a Floresta alcançou as maiores proporções quando comparado às outras unidades na mesma profundidade e sofreu um aumento em profundidade, $\mathrm{o}$ Ksat foi melhor na Floresta, nesta profundidade.

No que se refere às perdas totais de solo, observou-se, de uma forma geral, que as maiores perdas foram registradas na parcela A. Embora os valores totais das perdas tenham demonstrado maiores perdas na parcela A, quando comparadas estatisticamente, as perdas de solo das parcelas pelo teste T-Student, comprovou-se que não há diferenças significativas entre as tais perdas, uma vez que o $\mathrm{T}_{\mathrm{CALC}}(0,043)$ foi menor que $\mathrm{oT}_{\mathrm{TAB}}(1,99)$ para $\alpha=0,05$ e oGLIB $=$ 84.

O período mais crítico de perdas de solo (Figura 7) na parcela A ocorreu nos meses de dezembro e março. Em dezembro as perdas totalizaram 0,081 ton ha ${ }^{-1}$, nesse mês também foi registrada a maior taxa de escoamento do período, com apenas três eventos pluviométricos superiores a $40 \mathrm{~mm} \mathrm{dia}^{-1}$.

Diferente do observado no mês de dezembro, a taxa de escoamento de março não está entre as maiores do período. Entretanto, as perdas somaram 0,037 ton ha ${ }^{-1}$, inferior apenas às de dezembro, como afirmado acima. Com isso, conclui-se que a relação escoamento- erosão não é direta - outros fatores influenciam esse processo.

O processo de perdas de solo na parcela B distribui-se de forma diferente do que foi observado na parcela A. As maiores perdas da parcela B ocorreram nos meses de dezembro e janeiro, com aquele concentrando $45 \%$ das perdas de solo do período úmido e este concentrando $26 \%$.

Em dezembro as perdas alcançaram 0,073 ton $\mathrm{ha}^{-1}$, cerca de $11 \%$ a menos que o perdido na parcela A para o mesmo período. Para janeiro, as perdas totais foram de 0,041 ton $\mathrm{ha}^{-1} \mathrm{e} \mathrm{o}$ escoamento acumulado para esse mês foi de $10,73 \mathrm{~mm}$, o segundo maior do período. 
Essas diferenças de meses com os maiores picos de perdas de solo entre as parcelas estão diretamente relacionados à altura da vegetação, pois na área investigada, a área de pastagem é rotacionada para que as gramíneas possam se regenerar. A vegetação funciona como proteção natural do solo contra o impacto das gotas de chuvas e suas raízes contribuem para a percolação da água no solo, além de oferecer resistência ao escoamento da água não infiltrada durante a precipitação.

O maior pico de perda de solo no intervalo de 24 horas aconteceu no dia 24/12/2009, sendo 0,0523 ton $\mathrm{ha}^{-1}$ na parcela $\mathrm{Be} 0,0332$ ton $\mathrm{ha}^{-1}$ na parcela A. A precipitação neste dia alcançou os 47,43 mm. Essas perdas provavelmente estão mais relacionadas à intensidade da precipitação do que com seu volume total, pois apesar de a maior perda de solo ter sido registrada para esta data, a mesma não coincide com a altura máxima registrada de precipitação. Esse resultado é reforçado pelo teste de correlação de Pearson (Figura 8), que indicou uma relação fraca entre as variáveis precipitação e perdas de solo, sendo a parcela A com r=0,4211 e a parcela B com $\mathrm{r}=0,2548$.

Resultados semelhantes foram encontrados por Souza (2003) em áreas de parcelas com tratamento agrícola. As melhores correlações foram encontradas entre precipitação e escoamento.

Os baixos valores das correlações entre a precipitação total e as perdas de solo apontam que esses fatores não são diretamente proporcionais. Moretiet al (2003) afirmam que as características da chuva que proporcionam as correlações mais elevadas com as perdas de solo são a intensidade e a energia cinética. 

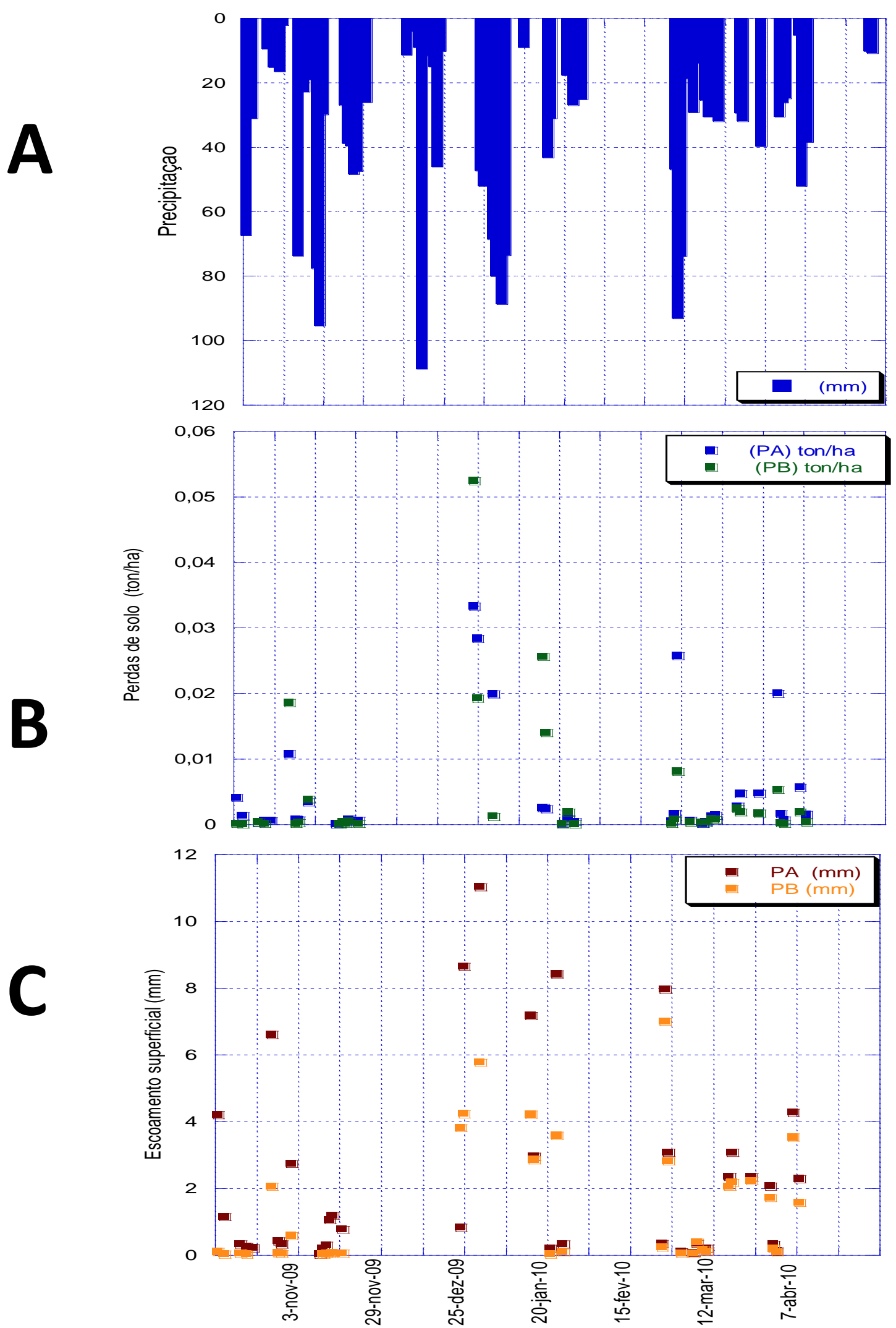
Figura7: (A)Gráfico de precipitação $(\mathrm{mm}), e(B)$ escoamento superficial $(\mathrm{mm})$ e $(C)$ perdas de solo em ton ha-1 relativos ao período de outubro de 2009 a março de 2010.
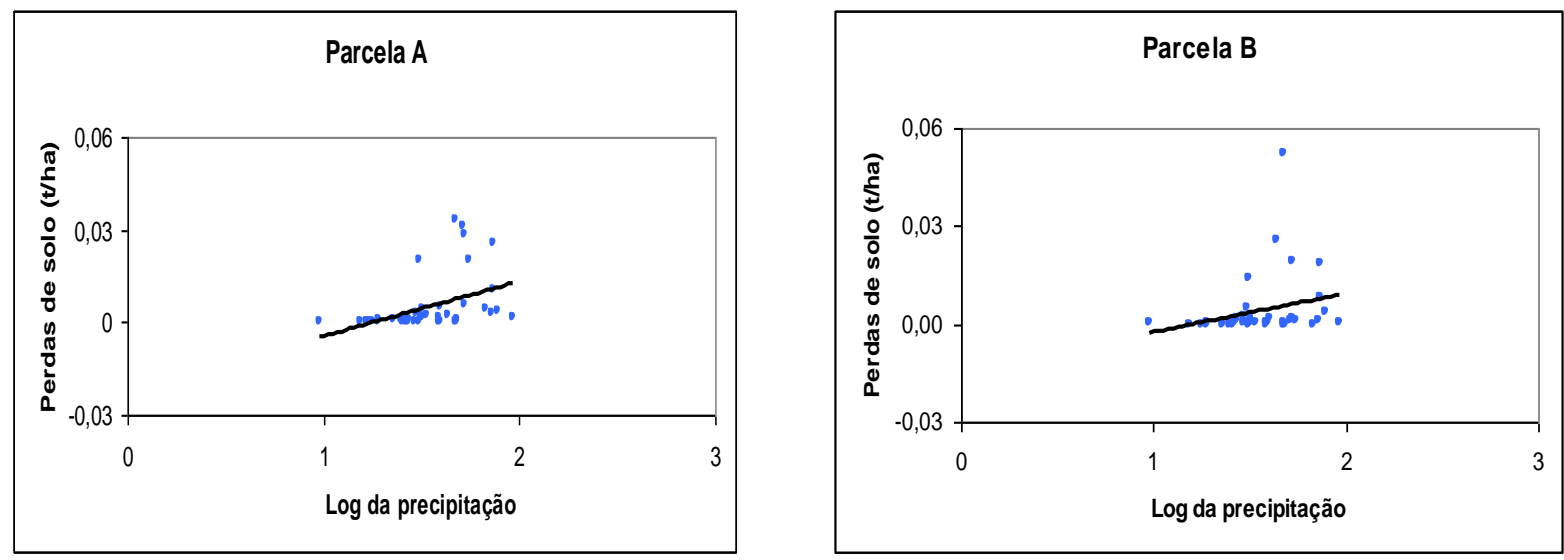

Figura 8: Correlação entre o log da precipitação e as perdas de solo (ton/ha) de cada parcela.

\section{CONCLUSÕES}

Os valores do Ksat nas parcelas foram diminuindo em profundidade, indo da ordem de $10^{-3}$ a $10^{-5}$, indicando uma redução da infiltração associada, provavelmente devido à atividade pecuária, à ausência de vegetação com raízes profundas e à compactação natural do solo em profundidade. Na Floresta, embora o valor de ksat a $15 \mathrm{~cm}$ e a $25 \mathrm{~cm}$ seja similar aos das parcelas, nos $45 \mathrm{~cm}$ ocorre um redução do valor do Ksat, ou seja, uma melhora da infiltração. Isto pode ser em decorrência da atuação de raízes profundas e da atuação da fauna, além de ser um indício de descontinuidade hidráulica.

Durante todo o período investigado, as maiores perdas totais de água e solo foram obtidas pela parcela $\mathrm{A}$, quando comparado com os totais da parcela $\mathrm{B}$ para o mesmo período. Esse resultado corrobora com os dados de condutividade hidráulica, no qual a parcela $\mathrm{A}$ apresenta Ksat médio menor, cerca de 10 vezes que a parcela B, o que corresponde a um menor potencial de infiltração. Com isso, nas condições da encosta A, uma maior quantidade das precipitações acaba escoando como fluxo laminar e as perdas totais de solo são maiores do que as registradas na encosta $\mathrm{B}$.

Parte desses resultados podem ser em decorrência dos micro-terraceamentos presentes na parcela $\mathrm{B}$, em decorrência do pisoteio do gado, que funcionam como barreiras para o escoamento, podendo favorecer a formação de poças nesses degraus.

Outro fator influenciador do processo hidroerosivo refere-se as características texturais. A parcela A não apresenta esses sinais de degradação, apesar de ser também uma área destinada à pastagem. Provavelmente, sua textura não favorece a formação desses degraus. A argila, presente em maioria na parcela $\mathrm{B}$, é facilmente modelável e oferece menor resistência à compactação.

Embora estudos detalhados sobre os processos hidroerosivos sejam onerosos e lentos, são de extrema importância para o desenvolvimento de políticas e medidas que visem à conservação do solo e da água. Portanto, apesar das limitações desse trabalho em inter-relacionar todas as variáveis presentes no processo erosivo, os resultados obtidos permitem uma caracterização desses processos nas colinas analisadas. Estas refletem a principal unidade geomorfológica utilizada para pastagem na região investigada. 


\section{LITERATURA CITADA}

BERTOL, I. et al. Propriedades Físicas do Solo Relacionadas a Diferentes Níveis de Oferta de Forragem numa Pastagem Natural. Revista PAB,Pesquisa Agropecuária Brasileira. volume 33, número 5, maio, 1998.

BIDEGAN, P. e C. M. VÖLCKLER.Bacias Hidrográficas dos rios São João e das Ostras Águas, terras e conservação ambiental. Araruama: CILSJ. 2003. 179 p.

BLANCO, A. J.L. Soil erosion fragility assessment using an impact model and geographic information system.Sociedade\&Natureza, Uberlândia, 20 (2): 157-175, dez. 2008.

DIAS-FILHO, M. B.Opções forrageiras para áreas sujeitas ao encharcamento ou alagamento temporário. Belém: EmbrapaAmazônia Oriental, 2006.

LAL, R. Physical management of the soils of the tropics: priorities for the 21st century. Soil Science, Baltimore, v. 165, n. 3, p.191-207, 2000.

MIGUEL F.R.M el al. Variabilidade espacial da infiltração de água em solo sob pastagem em função da intensidade de pisoteio. Pesq. agropec. bras., Brasília, v.44, n.11, p.1513-1519, nov. 2009.

MORAIS, N. B. Processos hidroerosivos em encostas de colinas com pastagem na bacia hidrográfica do alto curso do rio São João, Rio de Janeiro. 2011. Dissertação (Mestrado em PósGraduação em Geografia) - Universidade Federal Fluminense. Orientador: Raúl Sánchez Vicens.

OLIVEIRA, L. A. et al. Estudo Comparativo entre Condutividade Hidráulica e Textura de Latossolos Arenosos na Micro- Bacia do Córrego Perapitinga, Município de Ituiutaba/ MG. XIII SBGFA - Simpósio Brasileiro de Geografia Física Aplicada. Viçosa, 2007.

VIEIRA, B. C. Caracterização In Situ da Condutividade Hidráulica Saturada dos Solos e sua Influência nos Escorregamentos da Bacia do Rio Papagaio, Maciço da Tijuca (RJ). 2001. Dissertação (Mestrado em Geografia) - Universidade Federal do Rio de Janeiro. Orientador: Nelson Ferreira Fernandes.

ZACHAR, D. Erosion factors and conditions governing soil erosion and erosion processes. in.: Soil erosion. Developments in Soil Science Research Institute .Czechoslovakia. 1982. 